\title{
Catchment Size, Soil Type and Land Use to Determine the Amount and Likelihood of Flood in the Sarawak Corridor of Renewable Energy (SCORE) Region
}

\author{
Awang Abdillah, D.N.H., ${ }^{1}$ Selaman, O.S. ${ }^{2}$
}

\begin{abstract}
Size of catchment, soil types and land use are some of the factors that influence the flood phenomenon. Generally, the amount and behavior of the runoff from precipitation are analyzed to observe their effects on the catchment in terms of flood occurrence. This study measures the likelihood of flood event by comparing the peak flow rates at the pre development and post development stages of the major system. The approach used is by the most common practice in hydrology that is Rational Method. With a higher peak flow rate obtained at post development stage, it has been proven that as more urbanization takes place, there is the more flood occurrence. Similar results are obtained where the poorly-drained soils like peat and clay are present at certain area in the region. It has been verified that the size of catchment contributes the most on the flood risk.
\end{abstract}

Keywords: Catchment size, Soil types, Land use, Peak flow rate, Likelihood of flood occurrence

\section{INTRODUCTION}

LOOD occurs most commonly when there is excessive flow. Basically, the flow comes from heavy rainfall, from -1 melting ice and snow, or from a combination of these, that exceeds the carrying capacity of the river system, lake, or the ocean where it is conveyed. Therefore, an apt analysis is needed to be carried out based on the catchment characteristics that contribute to this problem.

This study is to determine the likelihood of flooding on Sarawak SCORE watersheds at which the flooding gives impact on the project and also which the project impacts flooding based on analysis with the intention of considerations of size of catchment, land use and soil types in varying conditions that give effects towards the water volume and its travel behavior due to changes occur by doing comparisons at conditions of pre development and post development.

Urbanization is a primary cause of nonhomogeneity of flood records [1]. MSMA:2000 stated that urbanization is the conversion of natural or rural areas into a residential, commercial or industrial development. Generally, the flood occurs because there are changes being made to the particular place which is referred to as land use changes. This happened due to the land surface modification in order to fulfill the human needs to ease them doing their activities on land, which then affect the runoff behavior that leads to flooding. Also, changes of soil types due to cut and fill works and land's soil modifications too, contribute to the problem [2]. Consequently, urbanization areas that keep increasing over time change the frequency of flood occurrence. These soils may be quite productive, but they have a flooding hazard that seriously limits their use for urban development or agriculture [3].

The influence of catchment size increases basically related to the amount of precipitation. As the catchment gets larger, then, the precipitation area, regardless the differences in the amount of rain fall into the regions [1]. The water will run on the land, which is called runoff, to the drains and river. Therefore, when the catchment is bigger, the runoff would be greater because it collects runoff from the entire specified area. When the catchment size is considered as large, it might be a highly flood-potential area [1]. This corresponds to the amount of the runoff collected over a period of time. 


\section{METHODOLOGY}

MSMA:2000 [4] stated that there are two ways to estimate peak flow, either by Rational Method or by hydrograph. The study comprises the pre development and post development stage. According to MSMA:2000, the peak flow at channel outlet at post development stage should not exceed the peak flow value of both minor and major system of pre development stage. The flood minor and major system flow is determined based on ARI values chosen. This is to ensure that the flood will not occur.

The peak flows, Q are compared to each other in its own development stage to see whether Q value is significant enough to cause flood based on the basins' flood history. Secondly, the Q value is compared among the same two basins, but at different development stages to see the impact of the SCORE development, by estimations.

MSMA:2000 stated that to Rational Formula is the most frequent approach used to do the flow peak computation and the formula is given as;

$$
\mathrm{Q}=\mathrm{CiA} / 360
$$

Where:

$$
\begin{array}{ll}
\mathrm{Q}= & \text { Peak rate of runoff in cubic meter per second } \\
\mathrm{C}= & \text { Runoff coefficient, an empirical coefficient representing the relationship between rainfall and runoff } \\
\mathrm{i}= & \begin{array}{l}
\text { Average intensity of rainfall for the time of concentration }\left(\mathrm{t}_{\mathrm{c}} \text { or } \mathrm{t}\right) \text { for a selected design storm in } \\
\mathrm{mm} / \mathrm{hr}
\end{array} \\
\mathrm{A}= & \text { Drainage area in hectares }
\end{array}
$$

To obtain the runoff coefficient, C MSMA:2000 gives;

$$
C_{\text {avg }}=\frac{\sum_{i=1}^{m} C_{i} A_{i}}{\sum_{i=1}^{m} A_{i}}
$$

Whereby;

$$
\begin{array}{ll}
\mathrm{C}_{\mathrm{avg}} & =\text { average runoff coefficient } \\
\mathrm{C}_{\mathrm{i}} & =\text { runoff coefficient for segment } \mathrm{i} \\
\mathrm{A}_{\mathrm{i}} & =\text { area of segment } \mathrm{i}(\mathrm{ha}) \\
\mathrm{i} & =1,2, \ldots, \mathrm{m} \\
\mathrm{m} & =\text { the number of different sub-catchment with different types of land use and soil type. }
\end{array}
$$

The land use map of scale 1:250,000 is obtained and downloaded from the website of www.library.wur.nl/isric/index2.html for the stage of pre development. The soil type data is obtained in the map form, purchased from the Agricultural Department of Sarawak. There are two sets of maps named Soil Map of Sarawak, Malaysia Timor 1968; Sheet A and Sheet B, of the scale of 1:500,000. For catchment size determination, the Department of Irrigation and Drainage Sarawak (DID) provides all the basin sizes in their website. Each basin have been prepared for their catchment characteristics whereby they are compiled in form of soil layers and land use layers to ease any task or comparison that is going to be performed, for that the data is gathered in a proper way.

As shown in figure 1, Sarawak consists of 21 river basins with different sizes and characteristics. Out of those, by referring to SCORE region as in figure 2, 10 river basins are used in this study namely; Baram, Niah, Suai, Similajau, Kemena, Rajang, Tatau, Balingian, Mukah and Oya. 


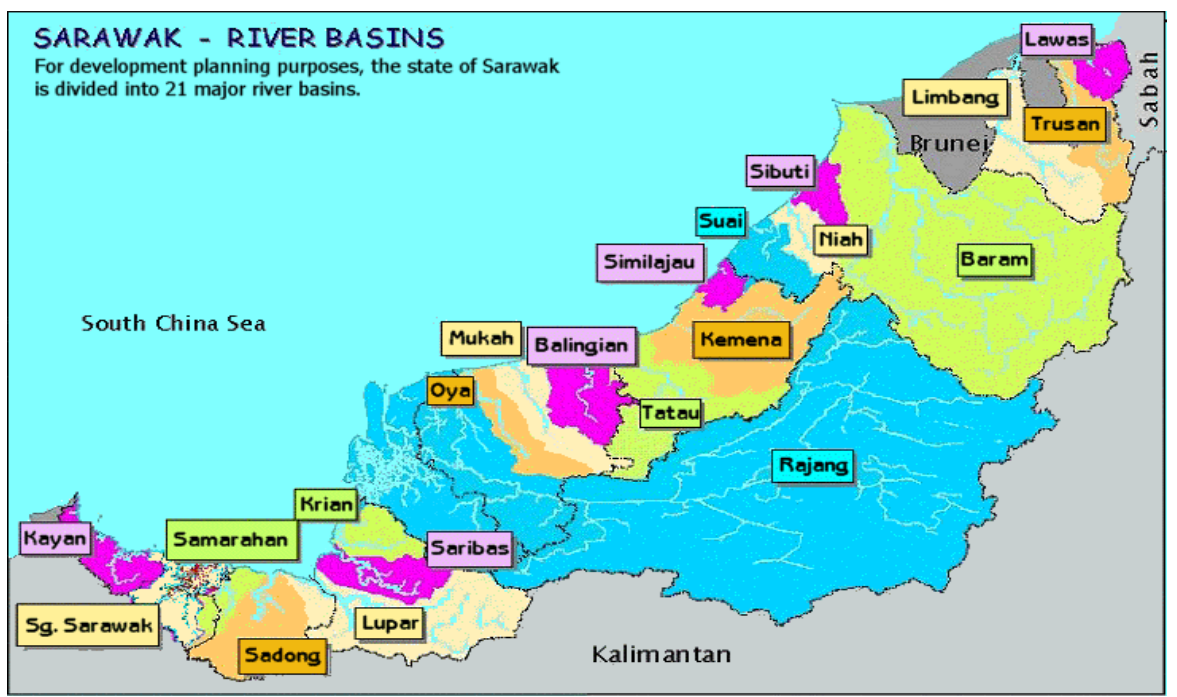

Figure 1: Sarawak River Basins Map. [5]
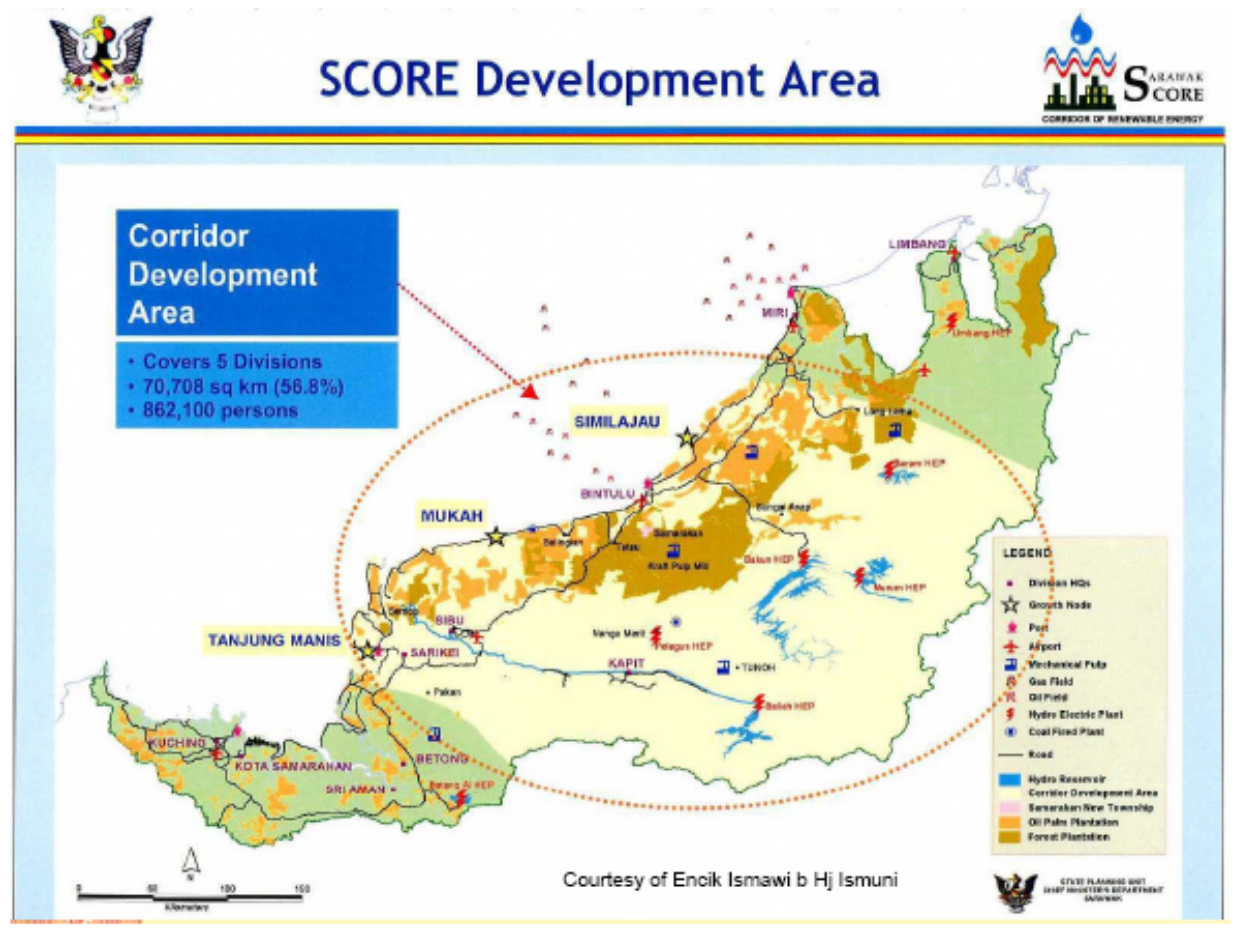

Figure 2: The scope of SCORE development area. [6]

\section{RESULT AND ANALYSIS}

The results are obtained for each different catchment in the SCORE region which are then compared to each other respect to the influence of size of basin, soil type and land use. Furthermore, results are also being compared at pre development and post development stages.

The runoff coefficient, $\mathrm{C}$ is analyzed by considering both soil type and land use of the basin. Like in figure 3 and figure 4, the details of Balingian basin existing type of soil and land use are indicated by the colors and the conclusions are shown in the text box. The $\mathrm{C}$ average is obtained by using (2). 
UNIMAS E-Journal of Civil Engineering, Vol. 1: issue 1/August 2009

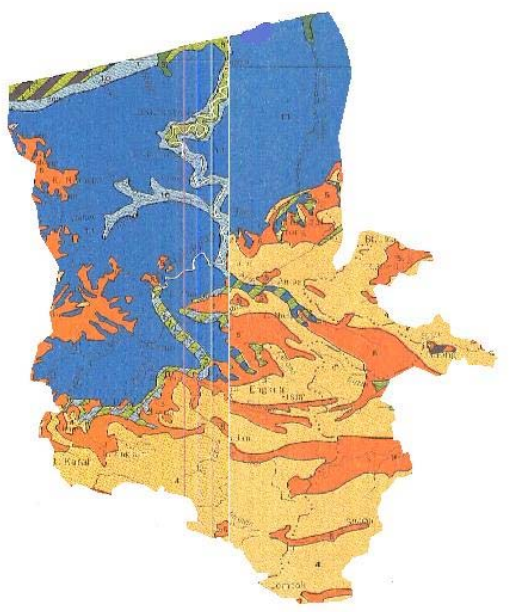

oil

Catchment name: Balingian

Area : 262500 ha

Major soil type(s): Peat, sandy clay

Figure 3: Balingian Soil Map. [7]

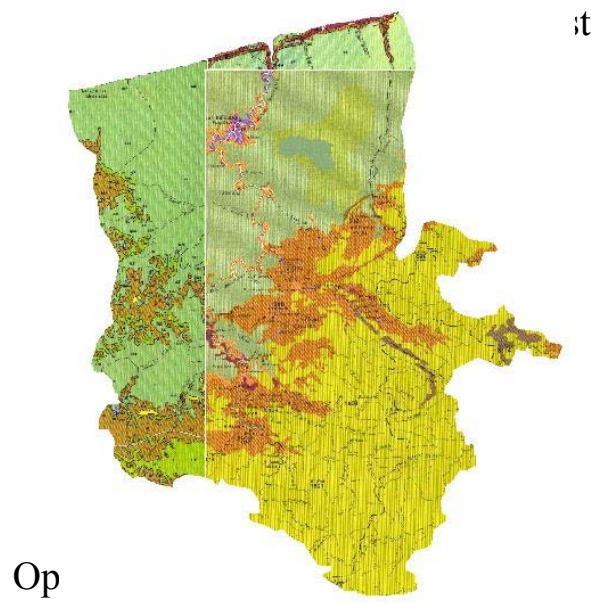

it

Catchment name: Balingian

Area : 262500 ha

Major land use: Forest and open crop

plantations

Figure 4: Balingian Land Use Map. [8]

Design rainfall intensity is tabulated in table 1 and it appears that the $i$ values for post development are always higher than those for pre development. This is because the ARI used are higher for post development stage, which is 20-year ARI, and higher ARI means rainfall data consists of larger rainfall intensities. 
Table 1: Design rainfall intensity

\begin{tabular}{|c|c|c|}
\hline \multirow{2}{*}{ Catchment } & \multicolumn{2}{|c|}{ i value (mm/hr) } \\
\cline { 2 - 3 } & $\begin{array}{c}\text { Pre development } \\
\text { Stage (5 years ARI) }\end{array}$ & $\begin{array}{c}\text { Post development stage } \\
\text { (20 years ARI) }\end{array}$ \\
\hline Oya & 111.337 & 140.685 \\
\hline Mukah & 111.337 & 140.685 \\
\hline Balingian & 111.337 & 140.685 \\
\hline Tatau & 124.281 & 148.445 \\
\hline Kemena & 124.281 & 148.445 \\
\hline Similajau & 124.281 & 148.445 \\
\hline Suai & 108.609 & 137.823 \\
\hline Niah & 108.609 & 137.823 \\
\hline Baram & 108.609 & 137.823 \\
\hline Upper Rajang & 93.6489 & 110.965 \\
\hline Lower Rajang & 111.337 & 140.685 \\
\hline
\end{tabular}

A comparison is needed to be carried out to analyze which factor affects the Q value the most. Therefore, table 2 below is prepared. In the table, as the catchment size increases, the $\mathrm{Q}$ values increases proportionally. While for $\mathrm{C}$ values, gives varying amount of flow rate as the $\mathrm{C}$ value increases, or in other words, the increment of $\mathrm{C}$ values are disproportionate to the $\mathrm{Q}$ values. Based on Rational Formula in which $\mathrm{C}$ value is supposed to increase the $\mathrm{Q}$ value proportionally as catchment size does, the results turns not to be as expected. This is mainly because of the catchment is very large, making the A value governs the $\mathrm{Q}$ value. For this SCORE project, it is clear that between the three factors, catchment size affects the likelihood of flood the most, followed by $\mathrm{C}$ value, which is a combination of both soil type and land use.

Table 2: Comparison of $\mathrm{Q}$ value to $\mathrm{A}$ value and $\mathrm{C}$ value

\begin{tabular}{|c|c|c|c|c|c|}
\hline & \multirow{2}{*}{$\begin{array}{c}\text { Catchment order } \\
\text { No. }\end{array}$} & \multicolumn{2}{|c|}{$\mathbf{Q}\left(\mathbf{1 0}^{\mathbf{6}} \mathbf{~ m}^{\mathbf{3}} \mathbf{s}\right)$} & \multicolumn{2}{c|}{ C } \\
\cline { 3 - 6 } & biggest to smallest size) & Pre development & Post development & Pre development & Post development \\
\hline 1 & Rajang & 449 & 624 & 0.79 & 0.87 \\
\hline 2 & Baram & 179 & 231 & 0.74 & 0.76 \\
\hline 3 & Kemena & 55.6 & 67.7 & 0.73 & 0.75 \\
\hline 4 & Tatau & 48.2 & 58.7 & 0.73 & 0.75 \\
\hline 5 & Balingian & 23.4 & 30.1 & 0.80 & 0.82 \\
\hline 6 & Mukah & 20.5 & 28.5 & 0.81 & 0.89 \\
\hline 7 & Oya & 19.2 & 24.7 & 0.80 & 0.82 \\
\hline 8 & Suai & 15.2 & 19.7 & 0.73 & 0.74 \\
\hline 9 & Niah & 10.5 & 13.6 & 0.72 & 0.74 \\
\hline 10 & Similajau & 5.66 & 7.43 & 0.71 & 0.78 \\
\hline
\end{tabular}

Due to lack of information regarding the areas of the development in SCORE project, the exact peak flow rate cannot be obtained simultaneously. Yet, there is still a way to simplify the determination for these discharges by deriving an equation for each catchment using the existing data. Derived from Rational Formula, these equations are easy to be used by any individual. Table 3 indicates the equations according to each basin concerned. 
Table 3: Flow peak, Q equation

\begin{tabular}{|c|c|c|}
\hline \multirow{2}{*}{ Catchment } & \multicolumn{2}{|c|}{ Flow peak equation } \\
\cline { 2 - 3 } & pre development & post development \\
\hline Oya & $0.309271\left(\sum \mathrm{c}_{\mathrm{i}} \mathrm{A}_{\mathrm{i}}\right)$ & $0.390792\left(\sum \mathrm{c}_{\mathrm{i}} \mathrm{A}_{\mathrm{i}}\right)$ \\
\hline Mukah & $0.309271\left(\sum \mathrm{c}_{\mathrm{i}} \mathrm{A}_{\mathrm{i}}\right)$ & $0.390792\left(\sum \mathrm{c}_{\mathrm{i}} \mathrm{A}_{\mathrm{i}}\right)$ \\
\hline Balingian & $0.309271\left(\sum \mathrm{c}_{\mathrm{i}} \mathrm{A}_{\mathrm{i}}\right)$ & $0.390792\left(\sum \mathrm{c}_{\mathrm{i}} \mathrm{A}_{\mathrm{i}}\right)$ \\
\hline Tatau & $0.345225\left(\sum \mathrm{c}_{\mathrm{i}} \mathrm{A}_{\mathrm{i}}\right)$ & $0.412346\left(\sum \mathrm{c}_{\mathrm{i}} \mathrm{A}_{\mathrm{i}}\right)$ \\
\hline Kemena & $0.345225\left(\sum \mathrm{c}_{\mathrm{i}} \mathrm{A}_{\mathrm{i}}\right)$ & $0.412346\left(\sum \mathrm{c}_{\mathrm{i}} \mathrm{A}_{\mathrm{i}}\right)$ \\
\hline Similajau & $0.345225\left(\sum \mathrm{c}_{\mathrm{i}} \mathrm{A}_{\mathrm{i}}\right)$ & $0.412346\left(\sum \mathrm{c}_{\mathrm{i}} \mathrm{A}_{\mathrm{i}}\right)$ \\
\hline Suai & $0.301692\left(\sum \mathrm{c}_{\mathrm{i}} \mathrm{A}_{\mathrm{i}}\right)$ & $0.382842\left(\sum \mathrm{c}_{\mathrm{i}} \mathrm{A}_{\mathrm{i}}\right)$ \\
\hline Niah & $0.301692\left(\sum \mathrm{c}_{\mathrm{i}} \mathrm{A}_{\mathrm{i}}\right)$ & $0.382842\left(\sum \mathrm{c}_{\mathrm{i}} \mathrm{A}_{\mathrm{i}}\right)$ \\
\hline Baram & $0.301692\left(\sum \mathrm{c}_{\mathrm{i}} \mathrm{A}_{\mathrm{i}}\right)$ & $0.382842\left(\sum \mathrm{c}_{\mathrm{i}} \mathrm{A}_{\mathrm{i}}\right)$ \\
\hline Lower + & $0.309271\left(\sum \mathrm{c}_{\mathrm{i}} \mathrm{A}_{\mathrm{i}}\right)$ & $0.390792\left(\sum \mathrm{c}_{\mathrm{i}} \mathrm{A}_{\mathrm{i}}\right)$ \\
\hline Upper Rajang & & \\
\hline
\end{tabular}

\section{CONCLUSIONS}

From the Q values obtained, it is indicated that Rajang catchment has the highest risk of flood occurrence because the basin gives the greatest flow rate among all basin, at both development stages. This corresponds to the flood history on the area that flood occurred more frequently there compared to other basins. Moreover, with further development, impervious areas will increase and the area is certainly would get flooded. Rajang is one good example to indicate how the $\mathrm{C}$ values and A values influence the flood phenomenon. As from the data collected, Rajang has the largest portion of peat soil which does not permit good drainage for precipitation. Rajang also has the biggest catchment area which means to collect the largest amount of runoffs. In contrast, Similajau has the smallest portion of peat soil, is least developed and has the smallest area of catchment. Consequently, it gives the smallest Q. It has been proven that the bigger the value of the above factors the bigger the $\mathrm{Q}$ value. Tanjung Manis, the main growth nodes for this project, is located in Rajang basin. Thus, several features must be planned carefully in order to minimize the risk. This study concluded that the likelihood of flood in SCORE region is determined that, Rajang has the highest probability, followed by Baram, Kemena, Tatau, Balingian, Mukah, Oya, Suai, Niah and Similajau. As understood, flood is affected by several factors that are not included in this study. Further study is recommended to be implemented to obtain more accurate and complete results.

\section{ACKNOWLEDGEMENT}

Special thanks are due to the Department of Irrigation and Drainage (Sarawak), Land and Survey Department of Sarawak and Department of Agriculture (Sarawak) for providing very useful information in order to carry out this study. Round of applause is given to Prof. Dr Wang Yin Chai of Faculty Information and Technology for his kindness and being helpful.

\section{REFERENCES}

[1] McCuen, Richard H.. (1989). Hydrological Analysis And Design. $1^{\text {st }}$ ed. New Jersey: Prentice-Hall

[2] Nelson, S.A. (2009). River Systems \& Causes of Flooding. http://www.tulane.edu/ sanelson/geol204/riversystems.htm/ 10 March 2009

[3] Headrick, Nevelyn. (2006). http://www.utahenvirothon.org/64.176.89.73/pdf/UTSoils.pdf/5 September 2008

[4] MASMA:2000. Urban Stormwater Management Manual for Malaysia (Manual Saliran Mesra Alam Malaysia). (2000). Department of Irrigation and Drainage,Malaysia.

[5] Department of Irrigation and Drainage. (2000). http://www.did.sarawak.gov/ 7 November 2008

[6] Mohamed, Murtedza. (2008). Participation of Sarawak Based Institutions of Higher Education in the Sarawak Corridor of Renewable Energy (SCORE) Development. http://www.unimas.my/images/stories/score/U-ScoreWebsite.pdf/ 22 October 2008

[7] Department of Agriculture Sarawak (2008). Soil Map of Sarawak, Malaysia Timor 1968; Sheet A and Sheet B. Malaysia.

[8] WAGENINGEN.(2009). World Soil Information Database. http://www.library.wur.nl/isric/index2.html/ 14 February 2009 